\title{
Effect of Ordinary Frequency High Electric Fields on Evaporation and Drying
}

\author{
Fumio Hashinaga, ${ }^{1}$ Ganga Prasad Kharel ${ }^{1}$ and Ryuichi Shintani ${ }^{2}$ \\ ${ }^{1}$ Faculty of Agriculture, Kagoshima University, 1-21-24, Korimoto, Kagoshima 890, Japan \\ ${ }^{2}$ Faculty of Science, Kwansei Gakuin University, 1-1-155, Uegahara, Nishinomiya 662, Japan
}

Received May 15, 1995

\begin{abstract}
Evaporation of water was enhanced by ordinary frequency $(60 \mathrm{~Hz})$ high electric fields (HEF), and the effect was directly proportional to the extent of treatment, i.e., increased with time and electric field, and decreased with separating head distance. Alternating current (AC) wire electric field was more effective in promoting evaporation of water than all direct currents (DC) and $\mathrm{AC}$ (plate) electric fields. As a result of the higher rate of evaporation, $\mathrm{AC}$ (wire) $\mathrm{HEF}$ caused a reduction of $1.0^{\circ} \mathrm{C}$ in the surface temperature in water and $4.5^{\circ} \mathrm{C}$ in ethanol. Both evaporation rate and surface temperature were resumed after the electric fields were discontinued. Furthermore, the evaporation rates of water and ethanol were equal to the respective controls after $60 \mathrm{~min}$ and $100 \mathrm{~min}$ of electric field cutoff, respectively. Similarly, HEF was very effective in promoting evaporation even at higher concentration of sugar or salt solutions. Cut discs ( size: $\phi 20 \mathrm{~mm} \times 10 \mathrm{~mm}$, ca. $174 \mathrm{~g}$, placed $10 \mathrm{~mm}$ apart on aluminum-foil) of apple flesh were dried under $\mathrm{AC}$ (wire) HEF under ambient conditions $\left(25^{\circ} \mathrm{C}, 35 \% \mathrm{RH}\right)$, and the higher the fields, the faster was the drying. After $10.0 \mathrm{~h}$ drying, the moisture contents of samples treated with $0.0,5.7,7.9$ and $10.0 \mathrm{kV}$ alternating electric fields ( $20 \mathrm{~mm}$ head distance) were $4.2,3.6,3.4$ and $3.1 \mathrm{~kg} / \mathrm{kg}$ dry solid, respectively.
\end{abstract}

Keywords: high electric fields, evaporation, drying

A number of applications of radio frequency or microwave dielectric heating in the food industry and agriculture were described by many authors (Nelson, 1987; Garcia et al., 1992; Bosisio et al., 1992). However, the effect of a high electric field (HEF) of ordinary frequency $(60 \mathrm{~Hz})$ on evaporation and its possible application in drying represent a new area of investigation. Until now, very limited information is available on this area. Asakawa (1976) performed a pioneering study on the influence of alternating electric fields on promotion and retardation of heat transfer. Evaporation of water increased many times due to the electric fields, and an alternating current (AC) field was more effective than a direct current (DC) field (Toda, 1990). It has been reported that HEF caused an increase in the evaporation rate of water and both electric and magnetic fields caused a depressed evaporation rate after treatment (Tanaka, 1991). The lethal effect of HEF on microorganisms (Sakurauchi \& Kondo, 1980) and the influence of high electric fields on germination of rice seeds have been described (Kondo \& Sakurauchi, 1983).

The main objectives of our study were to determine the effect of ordinary frequency HEF on the evaporation behavior of water and its application in the drying of foods.

\section{Materials and Methods}

Materials Water, alcohol, and different concentrations of salt and sucrose solutions were used to study the effect of the HEF. Cut discs (size: $\phi 20 \mathrm{~mm} \times 10 \mathrm{~mm}$, ca. $174 \mathrm{~g}$, placed $10 \mathrm{~mm}$ apart on aluminum foil) of apple flesh were used to show the influence of HEF to hasten drying over natural drying under ambient conditions.

Generation and conditions of HEF The samples were treated by HEF as shown in Fig. 1.

Conditions of HEF treatment:

a) $\mathrm{DC}(+)$ wire treatment: connected as shown in Fig. 1.

b) $\mathrm{DC}(-)$ wire treatment: same as Fig. 1 except the negative terminal from the rectifier (5) and the ground (12) are connected to the $\mathrm{Cu}$ wire (8) and the positive terminal is connected to the $\mathrm{Cu}$ plate (11).

c) DC (+) plate treatment: $\mathrm{Cu}$ wire of condition (a) is replaced by $\mathrm{Cu}$ plate.

d) $\mathrm{DC}(-)$ plate treatment: $\mathrm{Cu}$ wire of condition (b) is replaced by $\mathrm{Cu}$ plate.

e) AC wire treatment: ' $\mathrm{A}$ ' and ' $\mathrm{B}$ ' terminals of Fig. 1 are directly connected to $\mathrm{Cu}$ wire (8) and $\mathrm{Cu}$ plate (11) respectively.

f) AC plate treatment: $\mathrm{Cu}$ wire of condition (e) is replaced by $\mathrm{Cu}$ plate.

Evaporation measurement Two hundred milliliters of sample was poured into a $200-\mathrm{ml}$ beaker $(\phi 63 \mathrm{~mm})$ and weighed by a digital balance. Samples were treated with HEF (Fig. 1) as soon as possible after weighing. Similarly, samples were weighed as soon as possible after the electric field was cut off. Treated and non-treated samples were weighed in the same order to minimize error. Samples were treated with varying voltages, times and head distances $(H)$. The evaporation and evaporation rate were expressed as $\mathrm{kg} / \mathrm{h}$ and $\mathrm{kg} / \mathrm{m}^{2}$. $\mathrm{h}^{-1}$, respectively.

Temperature measurement An alcohol thermometer (div. $0.1^{\circ} \mathrm{C}$ ) was used because the mercury level in mercury thermometer is likely to break due to the HEF. The bulb of the thermometer was dipped in the surface of the water or ethanol to measure the surface temperature during the $\mathrm{HEF}$ 


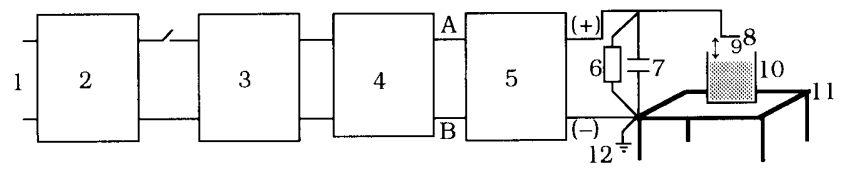

Fig. 1. Schematic diagram of electric field treatment. 1, electric source ( 100 V); 2 , voltage input regulator; 3 , fuse; 4 , step-up transformer; 5 , rectifier; 6 , safety resistor $(100 \mathrm{M} \Omega) ; 7$, condenser $(1320 \mathrm{pF}) ; 8, \mathrm{Cu}$ wire $(\phi 1 \mathrm{~mm} \times 20 \mathrm{~mm})$; 9 , head distance; 10 , sample; 11, Cu plate $(200 \mathrm{~mm} \times 300 \mathrm{~mm}) ; 12$, ground.



Fig. 2. Comparative effect of high electric field treatment on evaporation of water. Conditions: $200 \mathrm{ml}$ of water $\left(22.5^{\circ} \mathrm{C}\right)$ in $200-\mathrm{ml}$ beaker $(\phi 63 \mathrm{~mm})$ was treated with HEF $(8.6 \mathrm{kV}, 35 \mathrm{~mm}$ head distance) for $1.0 \mathrm{~h}$ under ambient conditions $\left(24^{\circ} \mathrm{C}\right.$ and $\left.35 \% \mathrm{RH}\right)$. ${ }^{*}$ with condenser plus resistor.

treatment.

Drying of apple flesh Apple flesh was cut into small pieces $(\phi 20 \mathrm{~mm} \times 10 \mathrm{~mm})$ and placed on aluminum foil at about $10 \mathrm{~mm}$ apart. Seventy-two $(8 \times 9)$ pieces (ca. $174 \mathrm{~g}$ ) were dried under ambient conditions $\left(25^{\circ} \mathrm{C}\right.$ and $\left.35 \% \mathrm{RH}\right)$. The treated sample was dried under HEF, whereas the control was dried under the same conditions but without HEF treatment. Moisture content was expressed as $\mathrm{kg} / \mathrm{kg}$ dry solid.

\section{Results and Discussion}

High electric fields under different conditions were produced as shown in Fig. 1. An alternating current (wire) electric field was more effective in enhancing the evaporation of water than $\mathrm{DC}(+)$ or $\mathrm{DC}(-)$ wire (Fig. 2). No difference in evaporation was found when either a condenser or a resistor was used. Under all conditions with the plate, the effect on evaporation was almost the same, but $\mathrm{AC}$ was more effective than DC in the case of the wire at constant electric fields ( $8.6 \mathrm{kV}$ and $35 \mathrm{~mm}$ head distance). The evaporation of water by AC or DC (plate), DC (wire) and AC (wire) was 1.4, 1.8 and 3.5 times greater than the control, respectively. The alternating current electric field caused more evaporation than the $\mathrm{DC}(-)$ or $\mathrm{DC}(+)$ electric fields.

The electric field was increased by reducing the head

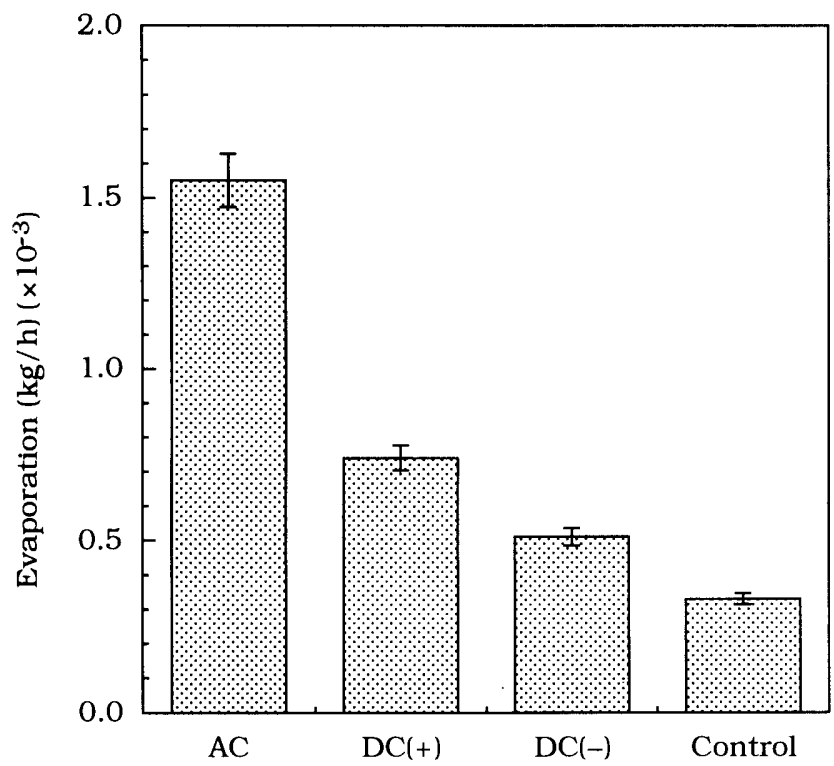

Fig. 3. Comparative effect of $\mathrm{AC}$ (wire) electric fields $(8.6 \mathrm{kV}, 20 \mathrm{~mm}$ head distance) treatment on evaporation of water. Condition: $200 \mathrm{ml}$ of water $\left(28^{\circ} \mathrm{C}\right)$ in $200-\mathrm{ml}$ beaker $(\phi 63 \mathrm{~mm})$ was treated as shown in Fig. 1.

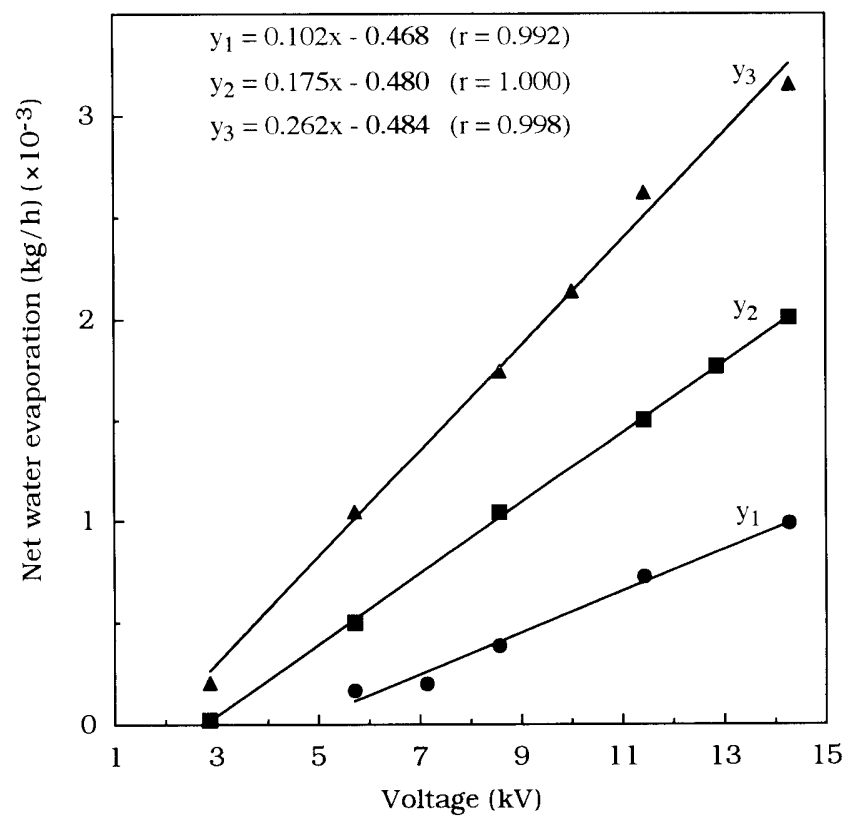

Fig. 4. Effect of $\mathrm{AC}$ (wire) electric field $(8.6 \mathrm{kV}, 20 \mathrm{~mm}$ head distance) treatment on net water evaporation (conditions are the same as in Fig. 3). $\boldsymbol{\bullet}, 0.5 \mathrm{~h}$ treatment; $\boldsymbol{\bullet}, 1.0 \mathrm{~h}$ treatment; $\mathbf{\Delta}, 1.5 \mathrm{~h}$ treatment.

distance (Fig. 1). Here, the DC (-), DC(+) and AC electric fields (wire) caused 1.5, 2.2 and 4.7 times more evaporation than the control. As the field strength increased, a difference between $\mathrm{DC}(+)$ and $\mathrm{DC}(-)$ was observed (Fig. 3).

The relationship of net water evaporation (evap. $(\mathrm{kg} / \mathrm{h})$ of sample - evap. $(\mathrm{kg} / \mathrm{h})$ of control) to the $\mathrm{AC}$ (wire) electric field was found to be linear. The net water evaporation was doubled and tripled when the treatment time was doubled and tripled for equal electric fields, respectively (Fig. 4). A similar result was reported by Asakawa et al. (1969). The 


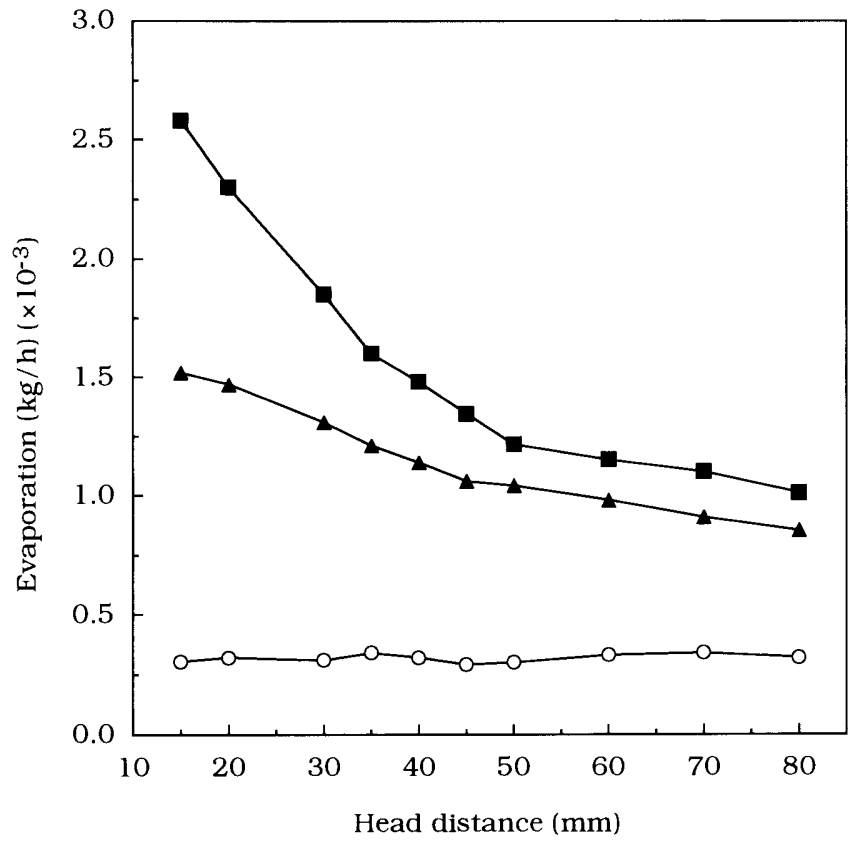

Fig. 5. Effect of head distance on evaporation of water under the influence of $\mathrm{AC}$ (wire) electric field treatment (conditions are the same as in Fig. 3). , control; $\Delta, 8.6 \mathrm{kV} ; \mathbf{\square}, 12.8 \mathrm{kV}$.

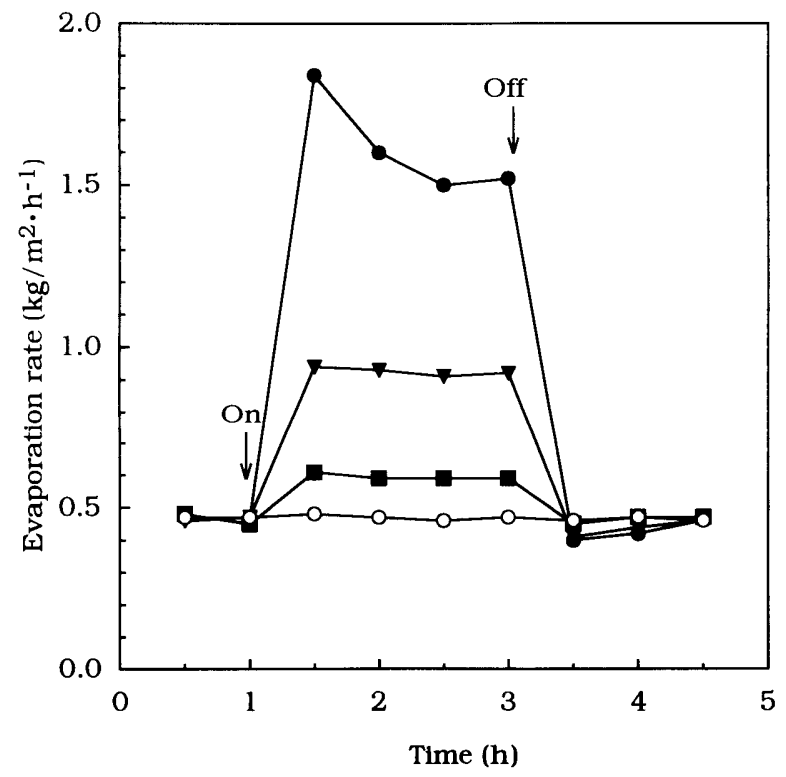

Fig. 6. Evaporation rate as a function of time for ethanol $\left(23^{\circ} \mathrm{C}\right)$ at different horizontal distances from the point of just below the $\mathrm{Cu}$ wire. $\mathrm{mm} ; \boldsymbol{\nabla}, 110 \mathrm{~mm} ; \boldsymbol{\square}, 220 \mathrm{~mm}$. Conditions: $40 \mathrm{ml}$ EtOH in a petri dish ( $\phi 92 \mathrm{~mm})$ was treated with AC (wire) HEF ( $10.0 \mathrm{kV}$ and $60 \mathrm{~mm}$ head distance) as in Fig. 1.

effect of head distances on evaporation of water is given in Fig. 5. Evaporation was abruptly decreased as the head distance increased to $50 \mathrm{~mm}$ in both electric fields. At the point of the highest electric field $(12.8 \mathrm{kV}$ and $15 \mathrm{~mm}$ head), the evaporation rate was 8.5 times that of the control.

An equal amount of ethanol at different distance from the wire was placed into identical petri dishes to determine the effectiveness of electric fields (Fig. 6). Ethanol was used because it is easier to evaporate than water under the influence

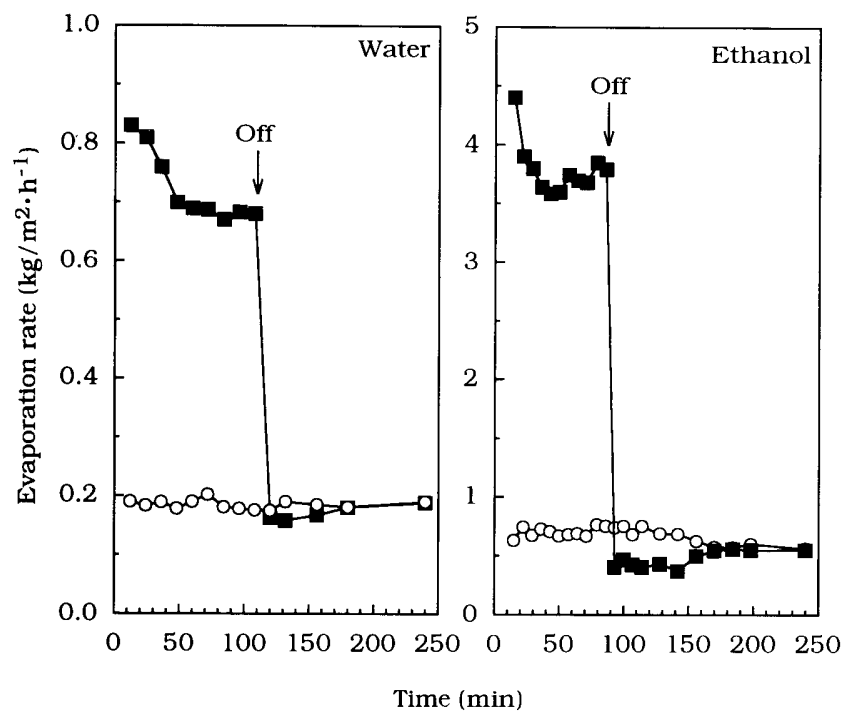

Fig. 7. Evaporation rate as a function of time for water $\left(28^{\circ} \mathrm{C}\right)$ and ethanol $\left(22^{\circ} \mathrm{C}\right)$ treated with $\mathrm{AC}$ (wire) HEF $(8.6 \mathrm{kV}$ and $20 \mathrm{~mm}$ head distance) (conditions are the same as in Fig. 3). ccintrol; $\mathbf{a}$, treatment.

of HEF. The aim of the experiment was to investigate the effect of horizontal distance on the evaporation rate of ethanol during the HEF treatment. As the horizontal distance from the wire (just below the wire was equal to $0.0 \mathrm{~mm}$ ) increased, the evaporation rate decreased. The evaporation rate of the sample at $220 \mathrm{~mm}$ horizontal distance was higher than the control. This indicates that HEF is effective in promoting the evaporation of ethanol further than $220 \mathrm{~mm}$ horizontal distance.

From Figs. 2-6, it was found that the evaporation of water or ethanol was directly related to the exposure period and electric field strength and inversely related to the distance from the wire. A similar relationship of evaporation to the strength of the electric field was reported (Asakawa et al., 1969). The time to attain the boiling point of water was one-half that of the control under the influence of alternating electric fields (Asakawa,1976). This phenomenon suggests that heat transfer may well be influenced by HEF. Tanaka (1991) explained that high speed ionic wind, which collides and transfers the energy to the surface of water molecules, carries the water molecules from the surface. Ionic wind is developed when the electric field is more than $4 \mathrm{kV} / \mathrm{m}$.

The evaporation rate of water and ethanol during and after HEF treatment was measured (Fig. 7). From Figs. 6 and 7, it can be explained that, under the influence of $\mathrm{HEF}$, a water or ethanol molecule was evaporated by absorbing heat energy from neighboring molecules. As a result, the evaporation rate during treatment progressively decreased (Fig. 6). Because the temperatures of treated and non-treated samples were different at the end of the electric field treatment (Fig. 8), the evaporation rate of treated water or ethanol abruptly decreased below that of non-treated samples. However, the evaporation rates of water and ethanol were recovered to that of the control after $60 \mathrm{~min}$ and $100 \mathrm{~min}$ of electric field cutoff, respectively. Accordingly, depression of the evaporation rate after HEF treatment was observed by Tanaka (1991) and 




Fig. 8. Changes in surface temperature of water and ethanol during and after HEF ( $8.6 \mathrm{kV}, 20 \mathrm{~mm}$ head distance) treatment. Dotted lines show temperature restoration to the control level when set at the minimum point of the treated samples. $\bigcirc$, control; $\mathbf{\nabla}$, treatment $(\mathrm{EtOH}) ; \mathbf{\square}$, treatment (water).

Kubota (1992), but how long the depression of evaporation occurred was not reported. The surface temperature of water and ethanol also showed a similar pattern (Fig. 8). During $\mathrm{HEF}$ treatment, the surface temperature was reduced $1^{\circ} \mathrm{C}$ in water and $4.5^{\circ} \mathrm{C}$ in ethanol. After that ( 40 min of treatment), no further temperature reduction was observed. Once the evaporation rate and surface temperature approached that of the control, no further difference was noticed between the control and the sample. Water and ethanol temperatures were restored to the level of the control faster than another control set at the minimum temperature of the treatments (shown by the dotted lines in Fig. 8). It is presumed that the depression of evaporation (Fig. 7) was mainly due to the decrease in surface temperature of the treated samples.

Changes in surface temperature during and after HEF treatment agreed with the pattern of evaporation during the same period (Fig. 7 and Fig. 8). However, a significant depression of the evaporation of water after electric and magnetic field treatment has been reported (Kubota, 1992; Tanaka, 1991). However, no information was available on the continuation of post-treatment effect.

The effectiveness of HEF at different molar concentrations of salt $(\mathrm{NaCl})$ and sugar (sucrose) solutions was determined (Fig. 9). HEF was very effective in causing evaporation even at high concentrations of sugar and salt solutions. Almost the same evaporation ratio was maintained up to $1.5 \mathrm{M}$ and then sharply decreased at $2 \mathrm{M}$ (saturation conc. at room temperature) sugar solution. In the case of salt solution, HEF was effective up to saturation (ca. $4.5 \mathrm{M}$ ) of the salt solution. This indicates that exposure to HEF may be effective during the concentration of high solute juices of fruits and vegetables.

Because evaporation of water is remarkably promoted in an electric field, its effect on drying was tested using cut pieces

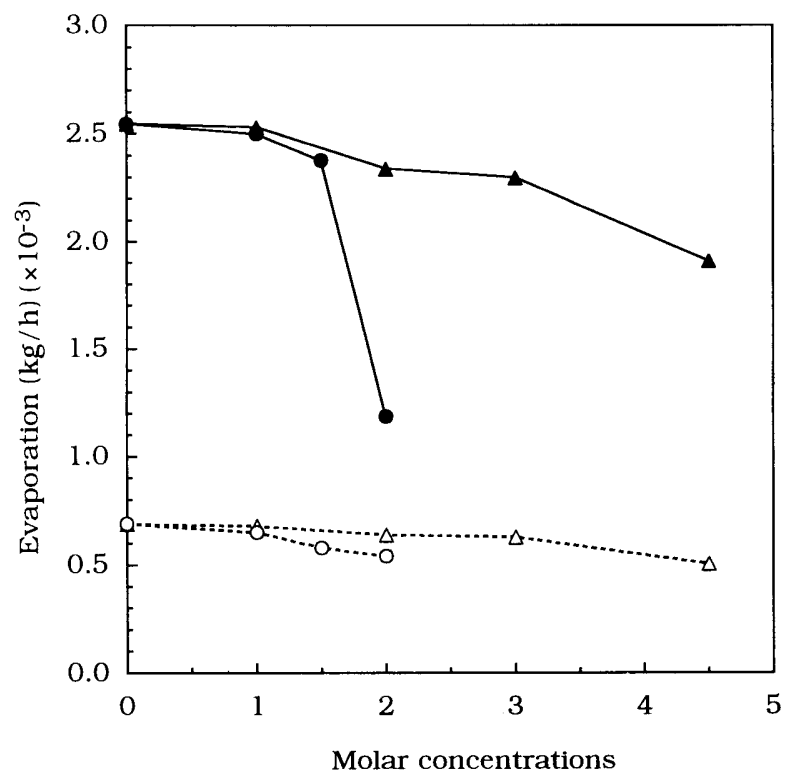

Fig. 9. Changes in evaporation of sugar and salt solutions at different molar concentrations when treated with $\operatorname{HEF}(8.6 \mathrm{kV}, 20 \mathrm{~mm}$ head distance) for 1.0 $\mathrm{h}$ (conditions are the same as for AC wire in Fig. 2). $\mathrm{O}$, control (sugar); treatment (sugar); $\triangle$, control (salt); $\Delta$, treatment (salt).

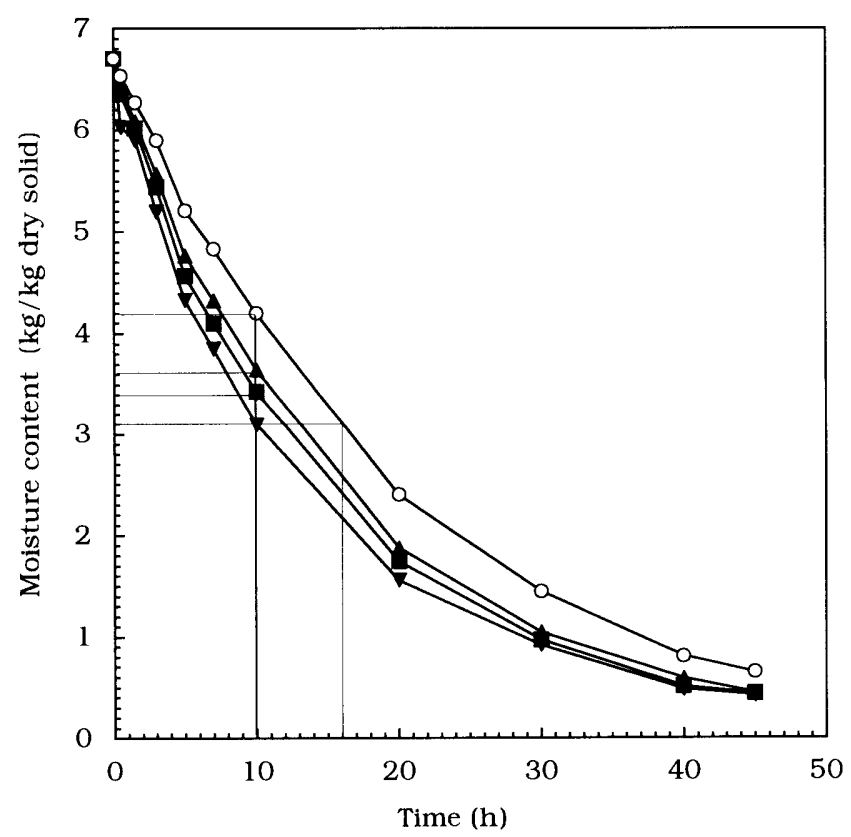

Fig. 10. Moisture content as a function of drying time under the $\mathrm{AC}$ (wire) electric field. $O$, control; $\boldsymbol{\Delta}, 5.7 \mathrm{kV}$ treatment; $\mathbf{\square}, 7.9 \mathrm{kV}$ treatment; $\boldsymbol{\nabla}, 10.0 \mathrm{kV}$ treatment. Conditions: Apple flesh $(\phi 20 \mathrm{~mm} \times 10 \mathrm{~mm})$ of $72(8 \times 9)$ pieces, ca. $174 \mathrm{~g}$ were placed $10 \mathrm{~mm}$ apart on aluminum foil and treated with $\mathrm{AC}$ (wire) HEF (20 mm head distance) under ambient conditions $\left(25^{\circ} \mathrm{C}\right.$ and $\left.35 \% \mathrm{RH}\right)$ (conditions are the same as in Fig. 1)

of apple flesh (Fig. 10). As expected, the higher the electric field, the faster was the drying. For instance, at $10.0 \mathrm{~h}$ drying time under ambient conditions $\left(25^{\circ} \mathrm{C}\right.$ and $\left.35 \% \mathrm{RH}\right)$, the moisture contents of samples treated with $0.0,5.7,7.9$ and 10.0 $\mathrm{kV} \mathrm{AC} \mathrm{(wire)} \mathrm{electric} \mathrm{fields} \mathrm{(} 20 \mathrm{~mm}$ head distance) were 4.2 , $3.6,3.4$ and $3.1 \mathrm{~kg} / \mathrm{kg}$ dry solid, respectively. To reduce to 
$3.1 \%$ (dry basis) moisture content, the control required $16 \mathrm{~h}$, whereas the AC treated sample required only $10 \mathrm{~h}$ of drying.

Based on the results described above, it can be concluded that ordinary frequency HEF can be used to increase the rate of evaporation and hence the drying and concentration of high solute juices of fruits and vegetables. It has been reported that no energy is absorbed from the electric field except for 1.5 to 2.0 watts as a result of ionization or leakage (Asakawa, 1976). In our experiments, the current between the wire and plate during HEF treatment $(8.6 \mathrm{kV}, 20 \mathrm{~mm}$ head distance) was nil. This shows that HEF may be applicable in dehydration, concentration, distillation and other unit operations where heat transfer is involved.

Acknowledgments The authors wish to express deep appreciation to Mr. W. Nakagawa, Murata Mfg. Co., Ltd., and to Mr. Kinugawa, FUJI Electric Co., Ltd., for providing the electric components.

\section{References}

Asakawa, Y., Ogawa, K. and Toda, S. (1969). Japan Society of Mechanical Engineers (JSME) Meeting (Thermal Problems), Paper $10,37-40$ (in Japanese).
Asakawa, Y. (1976). Promotion and retardation of heat transfer by electric field. Nature, 261, 220-221.

Bosisio, R.G., Shivhare, U.S., Raghavan, G.S.V. and Giroux, M. (1992). Surface wave applicator as a tool for microwave drying of particulates. In "Drying '92," ed. by A.S. Mujumdar. Elsevier Science Publishers B.V., pp. 1485-1492.

Garcia, A., Iglesias, O., Roques, M. and Bueno, J.L. (1992). Microwave drying of agar gels: kinetic parameters. In "Drying '92," ed. by A.S. Mujumdar. Elsevier Science Publishers B. V., pp. 595606.

Kondo, E. and Sakurauchi, Y. (1983). Influence of high electric fields on germination of rice plant seeds. Nippon Nogeikagaku Kaishi, $\mathbf{5 7}$ 1199-1202 (in Japanese).

Kubota, S. (1992). Water and foods and their freshness. Shokuhin Ryutsu Gijutsu, 21, 28-33 (in Japanese).

Nelson, S.O. (1987). Potential agricultural applications for RF and microwave energy. Trans. ASAE, 30, 818-822.

Sakurauchi, Y. and Kondo, E. (1980). Lethal effect of high electric fields on microorganisms. Nippon Nogeikagaku Kaishi, 54, 837-844 (in Japanese).

Tanaka, M. (1991). Preservation of foods in a fresh state and activation of water. Food Ind., 34, 27-33 (in Japanese).

Toda, S. (1990). Preservation of fruits and vegetables by the application of electric fields (English translation). Shokuhin Ryutsu Gijutsu, 19, 62-64 (in Japanese). 